\title{
Morning resolutions, evening disillusions: Theories of willpower affect how health behaviours change across the day
}

European Journal of Personality 202I, Vol. 35(3) 398-4I5

(C) The Author(s) 2020 Article reuse guidelines: sagepub.com/journals-permissions DOI: $10.1177 / 0890207020962304$ journals.sagepub.com/home/ejop

@SAGE

\author{
Zoë Francis', Jutta Mata ${ }^{2}$, Lavinia Flückiger ${ }^{2}$ and Veronika Job ${ }^{3}$
}

\begin{abstract}
People may be more or less vulnerable to changes in self-control across the day, depending on whether they believe willpower is more or less limited. Limited willpower beliefs might be associated with steeper decreases in self-control across the day, which may result in less goal-consistent behaviour by the evening. Community members with health goals (Sample I; $N=160 ;$ I8I4 observations) and students (Sample 2; $N=162 ; 10,581$ observations) completed five surveys per day for one to three weeks, reporting on their recent physical activity, snacking, subjective state, and health intentions. In both samples, more limited willpower beliefs were associated with less low- and moderate-intensity physical activity, particularly later in the day. Limited willpower beliefs were also associated with more snacking in the evenings (Sample I) or overall (Sample 2). These behavioural patterns were mediated by differential changes in selfefficacy and intentions across the course of the day (in Sample I), and the above patterns of low- and moderate-physical intensity held after controlling for related individual differences, including trait self-control and chronotype (in Sample 2). Overall, more limited willpower theories were associated with decreasing goal-consistent behaviour as the day progressed, alongside decreasing self-efficacy and weakening health-goal intentions.
\end{abstract}

\section{Keywords}

Lay theories, time of day, health, self-regulation

Received I3 August 2019; Revised I4 July 2020; accepted I6 July 2020

Pursuing a goal to make healthier choices often requires self-control, but self-control sometimes feels out of reach. Experiencing stress and demands throughout the day can make some people feel worn out by the evening - and that is when eating chocolate and lying on the couch might seem especially appealing. Research on trait variation in selfcontrol has shown that low self-control is related to more unhealthy eating, less physical activity, and less successful weight loss (Adriaanse et al., 2014; Crescioni et al., 2011; Willis et al., 2007). But selfcontrol does not only vary between people as a stable trait; it is also affected by contextual variables, resulting in substantial variation within each person. In particular, the willingness or ability to exert selfcontrol might decrease across the course of the day, potentially resulting in less health-focused choices as the day progresses. Some people may be particularly susceptible to this seeming decrease in self-control.

After people are exposed to temptations or use self-control, their apparent abilities to use subsequent self-control weakens, and tempting alternatives appear increasingly desirable (Baumeister et al.,
2007; Baumeister \& Heatherton, 1996; Blain et al., 2016; Inzlicht et al., 2014). Experience sampling studies on everyday desires suggest that people's abilities to resist a goal-conflicting desire (e.g., unhealthy food) change across the course of a day depending on either how much self-control they previously exerted or how many temptations they encountered (Hofmann et al., 2012; Milyavskaya \& Inzlicht, 2017; Wilkowski et al., 2018). Temporary decreases in selfcontrol - whether due to experimental fatigue inductions (Sellahewa \& Mullan, 2015) or due to fatigue naturally accumulating across the day (Boland et al., 2013) - are associated with making less healthy food

\footnotetext{
'Department of Psychology, University of Toronto, Toronto, Canada ${ }^{2}$ Division of Health Psychology, Department of Psychology, University of Mannheim, Mannheim, Germany

${ }^{3}$ Faculty of Psychology, Technische Universität Dresden, Dresden, Germany
}

Corresponding author:

Zoë Francis, University of the Fraser Valley, 33844 King Road, Abbotsford, British Columbia, V2S 7M8, Canada.

Email: zoe.francis@ufv.ca 
choices. Furthermore, after experimental self-control manipulations, some people sit longer in chairs (Job, Bernecker, et al., 2015, Study 5) and persevere less on their exercise routines (Dorris et al., 2012). Accumulating fatigue may be one factor leading to less healthy choices later in the day.

Across the course of the day, self-control failures may increase not only due to accumulating fatigue, but also due to an increasing necessity to use selfcontrol to make healthy decisions (Millar, 2017). For example, evening meal choices are driven less by habit than are morning meal choices (Khare \& Inman, 2006), suggesting that self-control may be more important to make healthy choices as the day progresses. Morning exercise is also more likely than evening exercise to be done habitually (Suresh, 2015). Furthermore, the relationship between stress and hunger is particularly strong later in the day (Huh et al., 2015), suggesting that people may require more self-control in the evenings to overcome emotion-driven hunger cues and resist overeating.

Unhealthy eating behaviours later in the day are of particular interest because evening behaviours may be more strongly associated with eating and health outcomes. Eating more later in the day has been associated with more food consumption overall (de Castro, 2004, 2009) and snacking late at night is associated with higher rates of obesity, binge eating, psychological distress (Colles et al., 2007) and coronary heart disease (Cahill et al., 2013).

Overall, self-control capacity may matter less in the morning, when health behaviours are more habit-driven and less likely to negatively impact overall health. Instead, self-control seems particularly important later in the day. Unfortunately, if mental fatigue also accumulates across the day, some people may be particularly vulnerable to evening self-control failures.

\section{Willpower theories}

While many people generally become more fatigued across the course of the day - with potentially negative health consequences - people do not all experience mental fatigue equally. Lay theories of willpower are one important factor in determining whether someone is easily fatigued or is more resistant to fatigue (Job et al., 2010; Salmon et al., 2014). People who think of willpower as more limited believe that using willpower is fatiguing, and that they need rest after strenuous work. Those who believe that willpower is less limited (more nonlimited), on the other hand, do not think that mental work is fatiguing. Those on the far end of the continuum, who hold a very nonlimited theory of willpower, believe that using willpower is energizing: the more work they do, the more they are prepared for further work (Savani \& Job, 2017).
Willpower theories are associated with a variety of real-world consequences (Francis \& Job, 2018). When under high demands, more limited willpower theorists engage in more procrastination, eat less healthily, and spend money more impulsively (Job, Walton, et al., 2015). Particularly after demanding days, a more limited willpower theory is also associated with decreased goal-striving (Bernecker \& Job, 2015b), which ultimately predicts lower subjective well-being (Bernecker et al., 2017) and higher body mass indices (BMIs; Bernecker \& Job, 2015a). Generally, more nonlimited willpower theories are associated with more goal-consistent behaviours, specifically in demanding and fatiguing situations.

While fatigue typically accumulates as the day progresses, we do not yet know whether willpower theory moderates how fatigue and goal-related behaviours change across the course of the day. People with more limited willpower theories, who experience decreased self-control after demanding situations, may be uniquely vulnerable to the accumulation of mental fatigue throughout the day. As a consequence, those with more limited willpower theories may be more likely to move around less and to snack more as the day progresses and their self-control wanes, particularly if being physically active or refraining from snacking involves self-control. Those who believe willpower is less limited (more nonlimited) tend to experience less mental fatigue, and thus may make more health-conscious choices later in the day, even when these healthy choices require self-control.

\section{Possible mechanisms}

Several mechanisms could account for a moderating effect of willpower beliefs on goal-related behaviours throughout the day. First, limited willpower theorists might fail to adhere to their goals due to reduced selfcontrol strength (Baumeister et al., 2018). If limited willpower theorists have especially weakened selfcontrol later in the day, they may be unable to maintain their goals despite setting good intentions. This might be reflected in a weaker relationship between intentions and subsequent behaviour for limited willpower theorists, compared to nonlimited theorists, especially later in the day.

Alternatively, willpower theories might affect how people view themselves and their ability to succeed at their goals. Self-efficacy - one's belief in their ability to succeed - is an important predictor of health behavioural change (AbuSabha \& Achterberg, 1997; Nezami et al., 2016). Those with a more limited willpower theory might be aware that they tend to fail at their goals later in the day, and might thus report feeling less self-efficacious. Previous research has documented reduced momentary self-efficacy among limited theorists after exerting self-control, which explained their reduced self-control performance (Chow et al., 2015). Although behavioural effects of 
willpower theories are not mediated by differences in overall trait self-efficacy (e.g., Bernecker \& Job, 2015b), limited theorists may have lower momentary self-efficacy during times of high demand, which may contribute to setting less ambitious health intentions for themselves. Failing to set intentions could then affect their subsequent health behaviours (McDermott et al., 2016; Papies, 2016). We will test whether self-efficacy and health intentions vary across the course of the day differently depending on one's willpower theory, and, if so, test whether these variables might mediate differences in health behaviour patterns.

Finally, subjective feelings of fatigue or negative affect might mediate patterns of goal-inconsistent behaviour. More limited willpower theories tend to be associated with higher reported fatigue and positive affect (Bernecker et al., 2017). Subjective affect, in turn, can affect snack consumption; restrained eaters eat more when experiencing negative affect, and most populations eat more when experiencing positive affect (Evers et al., 2018). Subjective affect or fatigue could be separate mechanisms for changes in behaviour across the course of the day. Alternatively, these changes in subjective state might co-occur with reduced self-control capacity or reduced self-efficacy.

\section{The current studies}

Using experience sampling, two samples of participants recorded their physical activity, snacking, and fruit and vegetable intake across the course of the day, as well as their subjective emotions and their health-related intentions. We focused on how changes in behaviours across time-of-day are moderated by theory of willpower. This is the first study, to our knowledge, to examine whether willpower theories might predict time-of-day effects on self-regulatory behaviours; time-of-day effects are receiving increasing attention from both self-control and health researchers (reviews in Curtis et al.,2014; Millar, 2017).

We predicted that stronger belief in a limited willpower theory would predict steeper declines in selfcontrol over the course of the day. Specifically, we assumed that more limited theorists, relative to less limited theorists, would report increases in healthgoal incongruent behaviours (snacking) across the day, and relative decreases in health-goal congruent behaviours (physical activity, fruit and vegetable intake) across the day. Health intentions, selfefficacy, and subjective state were examined as potential mediators of changes in health behaviours.

These hypotheses were tested in two samples. Sample 1 consisted of community members who were recruited due to being unsatisfied with their current nutrition or physical activity. Our replication sample (Sample 2) consisted of undergraduate students who were recruited for a study on academic goals and achievements. Analyses done on the first sample should be considered exploratory, while the identical analyses conducted on the replication sample should be considered confirmatory. Neither study was preregistered. We present results from both samples simultaneously, so that the findings in Sample 1 are placed in the context of the replication findings from Sample 2.

\section{Methods}

\section{Participants}

Sample 1. One hundred and sixty German-speaking participants completed the Willpower Theory questionnaire (during the initial survey or, if not, at the mid-experiment survey $(N=11)$ ) and at least one experience-sampling survey. Two additional participants were excluded because their responses were more than $6 \mathrm{~h}$ different than other participants' (meaning they might have either been in other time zones or using proxies). Participants' were predominantly female $(81 \%)$, and were between 18 and 65 years old $(M=27.86, S D=9.74)$.

Across participants, 1814 experience-sampling surveys were completed, distributed across five survey time-points per day (Table 1). Participants each completed between 1 and 48 experience-sampling surveys, with a mean of $11.34(S D=11.11)$ and a median of seven surveys completed per participant. See Supplemental Materials for recruitment procedure (S1.1) and analysis of potential correlates of completion rates - survey completion was not significantly related to BMI, willpower theory, or any other individual difference (S1.2). The overall completion rate was quite low - in the first week of sampling, the average completion rate was $26 \%$. Only 47 participants returned for a second week, and completed $20 \%$ of their second week surveys. While survey completion was not related to individual differences, and research suggests that completed surveys do not noticeably differ from missed surveys (Sun et al., 2020), we address this limitation by replicating analyses in a second sample with a higher survey completion rate.

Replication Sample 2. Undergraduate students $(N=162)$, with a mean age of $22.0(S D=3.99)$ participated in this study for course credit or monetary reimbursement of up to 170 Swiss Francs, depending on the number of surveys completed. This dataset was also used for Study 2 of Sieber et al. (2019). Like Sample 1, this sample was predominantly female (127 women, 27 men, 8 unspecified). Unlike the community member participants in Sample 1, student participants in Sample 2 were not recruited based on having health improvement goals, and the sample was significantly younger $(d=0.79, p<.001)$ with lower BMIs $(d=0.80, p<.001)$. 
Completion rates of Sample 2 were much higher than Sample 1. Out of a possible 105 experiencesampling surveys per person (five times per day, for three week-long periods), participants completed a median of 75.5 surveys $(M=65.31, S D=25.40)$, ranging from 1 to 97 ( $72 \%$ completion rate). Overall, 10,581 experience-sampling surveys were completed. Due to the substantially higher number of observations per person, Sample 2 had higher statistical power to provide confirmatory tests of the within-subject effects found in Sample 1. Like in Sample 1, survey completion was not related to any analysed trait variable or to BMI (see Supplemental Materials S1.2).

For both samples, all data collection was completed prior to any analyses being conducted. Sample sizes were originally selected based on betweensubject hypotheses (e.g., $N=160$ has $80 \%$ power to detect $r=.20$ ).

\section{Procedure}

Participants provided informed consent and completed a set of initial questionnaires, including the willpower theories questionnaire and demographics questions. Starting on the following Sunday, participants in Sample 1 were sent short surveys (4 to $5 \mathrm{~min}$ long) via their smartphones five times a day, for seven consecutive days. Each of the five daily surveys were sent randomly to participants within five time blocks throughout the day - between 8:30 a.m. and 11 a.m., 11 a.m. and 1:30 p.m., 1:30 p.m. and 4 p.m., 4 p.m. and 6:30 p.m., and 6:30 p.m. and 9:00 p.m. - with a minimum of $30 \mathrm{~min}$ between surveys. Participants had to respond within $45 \mathrm{~min}$. These experiencesampling surveys asked about current feelings, intentions and behaviours from the previous 2 to $3 \mathrm{~h}$, among other items (see Supplemental Materials S1.3). Participants in Sample 1 were invited back to complete another seven days of identical experiencesampling surveys eight weeks later. ${ }^{1}$ Participants in Sample 2 completed one week of experiencesampling surveys at the beginning of the term, one week in the middle of term, and one week at the end of term.

\section{Measures}

Willpower Theory. Willpower theories were measured with a 16-item version of the extended Implicit Theories of Willpower scale (Bernecker \& Job, 2015a; Job et al., 2010), and treated as a continuous variable for all analyses. The extended scale measures the belief that engaging in four different types of activities - mental effort, physical effort, resisting temptations and overcoming tasks - results in exhaustion and a need for a break. Each item is measured on a six-point scale, from strongly agree to strongly disagree, and half of the items are reverse-scored 
(Sample $1 M=3.61, S D=0.62, \alpha=.83,95 \%$ CI [0.80, $0.87]$; Sample $2 M=3.00, S D=0.58, \alpha=.80,95 \% \mathrm{CI}$ $[0.75,0.85])$. Items include, "After an activity I had to overcome (e.g. tidying up or exercising), my willpower is exhausted and I have to rest to replenish it" and "After a physically strenuous activity, I feel full of energy and can go on with something very demanding" (reverse-scored).

$B M I$. Participants reported their height (in meters) and weight (in $\mathrm{kg}$ ) in the initial set of questionnaires, which we then used to calculate their BMI $\left(\mathrm{kg} / \mathrm{m}^{2}\right)$.

Chronotype, self-control, and depression (Sample 2). At baseline, participants in Sample 2 also completed the following related individual difference measures: (i) the German translation of the 5-item Reduced Morningness-Eveningness scale (Adan \& Almirall, 1991), scored such that higher values indicate more "morningness", to determine chronotype $(\alpha=.66,95 \%$ CI $[0.65,0.67])$; (ii) the German brief trait self-control scale $(\alpha=.83,95 \%$ CI [0.83, 0.84]; Bertrams \& Dickhäuser, 2009; Tangney et al., 2004); and (iii) the 20-item German Center for the Epidemiologic Studies Depression scale to measure depression $(\alpha=.90,95 \%$ CI [0.90, 0.91]; Hautzinger $\&$ Bailer, 1993; Radloff, 1977). These measures were analysed to ensure that any relationships between willpower theories and health behaviours across the day could not be better explained by related individual differences.

Momentary intentions. In the first survey of the day, participants (in both samples) were asked about the strength of their intentions to be physically active, to do without snacks, and to look after their fruit and vegetable intake that day. Each intention was measured by one item $(1=I$ do not have that intention, $10=I$ have that intention very strongly). Participants in Sample 1 were also asked about their intentions at each of the other four surveys across the day, where the question specifically asked about their intentions for the upcoming 2 to $3 \mathrm{~h}$, instead of about their intentions for the upcoming day.

Momentary fatigue, affect, and self-efficacy. For participants in both samples, subjective state was measured using seven-point response scales $(1=$ not at all, 7 =extremely), across 11 different emotional adjectives. Three adjectives - worn-out, energized, and relaxed - were aggregated as a measure of fatigue (first survey Sample $1 \alpha=.87$; first survey Sample 2 $\alpha=.89$ ). Five adjectives - content, depressed (reversescored), happy, sad (reverse-scored), and pleased were aggregated as a measure of subjective affect (first survey Sample $1 \alpha=0.85$; first survey Sample 2 $\alpha=.85)$. The other items, corresponding to goalrelated emotions (frustrated, ashamed, and guilty), were not analysed.

In Sample 1 only, we also measured general selfefficacy by asking participants how much they felt capable and able to do all of their tasks in the upcoming 2 to $3 \mathrm{~h}$.
Recent physical activity, snacking, and fruit and vegetable intake. In both samples, participants reported on their actual health behaviours since waking up (for the first survey of the day) or since the last survey prompt (2-3 h prior). For physical activity, participants indicated how many minutes they had spent on low-intensity physical activity (e.g., comfortable walking, stretching), moderate-intensity physical activity (e.g., fast walking), and high-intensity physical activity (e.g., jogging; Godin \& Shephard, 1985; adapted for experience-sampling by Mata et al., 2012). For snacking behaviour, participants separately reported the number of salty, sweet, greasy, and other snacks that they had consumed, where a snack was defined as any food eaten outside of a meal. For analysis, we summed these four categories of snacks (excluding snacks of fruits and vegetables, which were analysed separately). For fruits and vegetable consumption, participants indicated how many servings of fruits or vegetables they had eaten, where one serving was defined as the size of their fist.

\section{Analysis}

For each analysis, we examined how willpower theory, time-of-day, and the interaction between willpower theories and time-of-day predicted the outcomes of health behaviour intentions and health behaviours. Time-of-day was treated as a linear variable, based on the submission time of the survey response, analysed in units of hours. See Supplemental Materials (S2) for discussion of nonlinear time-of-day effects.

Analyses were conducted using multi-level models, with observations nested within days within participants (random intercepts). ${ }^{2}$ For models that still could not converge due to insufficient degrees of freedom, participant was the only random variable (Jaeger, 2009; cf. Eager \& Roy, 2017). Individual difference measures, including willpower theories and age, were grand-mean centred. Level-1 predictor variables, like state self-efficacy and intentions, were person-centred. Interactions were further analysed using simple slopes (West et al., 1996). Time-of-day was grand-mean centred (around 2 p.m.), so that the time-of-day variable retained its meaning consistently across participants. Results remained virtually identical when using a person-centred time variable. Behaviour intentions, self-efficacy, and affect were analysed using the lmer package in $\mathrm{R}$ (Bates et al., 2015). Effect sizes are reported using the square root of semi-partial $R^{2}$ (Edwards et al., 2008). Reported physical activity, snacks, and fruits and vegetable intake were non-normally distributed count data, and intentions to be physically active were also highly positively skewed, so analyses with these outcome variables used the glmer function with a Poisson distribution. Due to associations between age and both BMI and physical activity (Colley 
et al., 2011), we controlled for age in all behavioural analyses.

Analysis of the first sample was exploratory. After finishing all analyses of the first dataset, we conducted an identical set of analyses on the replication sample, substantially reducing our analyses' degrees of freedom and better controlling our error rate (Gelman \& Loken, 2013). We further conducted planned analyses of Sample 2 to confirm that moderation by willpower theory could not be better explained by moderations by other related individual differences: trait selfcontrol, depression, or chronotype. When exploratory analyses were conducted within the replication sample, we have clearly identified them as such. Study materials, data for the current analyses, and $\mathrm{R}$ analysis scripts are available at: https://osf.io/ vyxw7/.

\section{Results}

\section{Descriptives}

Sample 1. In an average time period of 2 to $3 \mathrm{~h}$, participants generally reported 15.40 min of low-intensity activity $(S D=37.54$; median $=5)$ and $9.39 \mathrm{~min}$ of moderate-intensity activity $(S D=26.18 ; 65 \%$ of surveys reported zero). Participants rarely engaged in high-intensity physical activity and reported $0 \mathrm{~min}$ on $90 \%$ of surveys. Per time period, community participants reported an average of 1.09 snacks $(S D=1.48)$. The data were right-skewed, such that $48 \%$ of reports indicated no snacks had been consumed in the specified time before the survey (see Table 1 for means by time-point). See Table 1 for descriptions at each survey.

Replication Sample 2. In the student sample, participants generally reported $8.03 \mathrm{~min}$ of low-intensity activity $(S D=16.19 ; 55 \%$ of surveys reported zero) and $2.79 \mathrm{~min}$ of moderate-intensity activity $(S D=13.37 ; \quad 88 \%$ of surveys reported zero). Participants reported 0 min of high-intensity activity $93 \%$ of the time (leaving 754 non-zero instances). Student participants reported snacking less than community participants, with an average of 0.51 snacks $(S D=1.00)$, including $67 \%$ of reports indicating no snack had been consumed since the previous survey.

\section{BMI}

Sample 1. The community sample had an average BMI of $24.61(S D=4.93)$, with $35 \%$ of participants being either overweight $(n=38)$ or obese $(n=14$; unknown BMI $n=12$ ). A more limited willpower theory was associated with higher BMI $(B=-1.27$, $S E=0.59, t(145)=-2.16, p=.032, r=.18)$ after controlling for age $\left(B_{\text {age }}=0.21, S E=0.04, F(1,145)=\right.$ 31.81, $p<.001, r=.42)$.

Replication Sample 2. Average BMI was considerably lower in Sample $2(M=21.41, S D=2.80)$, with only $8.3 \%$ of participants being overweight $(n=8)$ or obese $(n=3)$. Despite these differences, a more limited willpower theory was again correlated with higher BMI $(r=.18,95 \%$ CI $[0.013,0.340], p=.035)$. This relationship held when controlling for age, trait selfcontrol, chronotype, and trait depression (with covariates, $\quad B_{\text {willpower }}=0.97, \quad S E=0.43, \quad t(125)=2.26$, $p=.026, r=.20$ ), none of which were significantly related to BMI themselves (Table 2) except for age $(B=0.14, S E=0.07, t(125)=2.11, p=.037, r=.19)$.

\section{Physical activity across the day}

Sample 1. Using three-level hierarchical models and specifying a Poisson distribution, we examined how patterns of physical activity changed across the course of the day depending on one's willpower theory, controlling for age. Low- and moderate-intensity physical activity both increased across the course of the day as main effects (low $B=0.035, S E=0.002, z=14.31$, $p<.001$; moderate $B=0.058, S E=0.003, z=19.85$, $p<.001)$. However, physical activity increased across the course of the day to different extents depending on willpower theories (Figure 1; lowintensity interaction $B=-0.017, \quad S E=0.004$, $z=4.84, \quad p<.001 ;$ moderate-intensity $B=-0.031$, $S E=0.005, \quad z=6.91, \quad p<.001)$. Both low- and moderate-intensity physical activity increased more across the day for those with more nonlimited theories. For example, a nonlimited theorist (at $1 S D$ below the mean) increased their low-intensity physical activity by almost $5 \%$ per hour $(B=0.045$, $S E=0.003, z=13.66, p<.001)$, while a limited theorist (at $1 S D$ above the mean) increased their lowintensity physical activity by only $2.5 \%$ per hour $(B=0.025, S E=0.003, z=7.78, p<.001)$. Neither low-intensity nor moderate-intensity physical activity was related to willpower theories overall (low-intensity $B=0.10, S E=0.27, z=0.37, p=.71$; moderateintensity $B=-0.35, S E=0.32, z=1.09, p=.28$ ).

Because participants recorded $0 \mathrm{~min}$ of highintensity activity $90 \%$ of the time, we conducted a binomial multi-level analysis on whether or not any high-intensity activity occurred. The occurrence of high-intensity physical activity was only predicted by time-of-day. Like lower intensities of activity, high-intensity exercise was more likely later in the day $(B=0.15, \quad S E=0.03, \quad z=4.79, \quad p<.001)$. Willpower theory was not related to the occurrence of high-intensity activity, neither overall $(B=-0.16$, $S E=0.26, z=0.62, p=.53)$ nor did it moderate the increase in high-intensity activity across the course of the day $\left(B_{\text {interaction }}=-0.04, \quad S E=0.05, \quad z=0.86\right.$, $p=.39$ ).

Replication sample. Reported minutes of physical activity, of every intensity level, again typically increased as the day progressed (low-intensity $B=0.009, S E=0.001, z=8.84, p<.001$; moderate $B=0.04, \quad S E=0.002, \quad z=22.60, \quad p<.001 ; \quad$ high 
Table 2. Zero-order correlations between individual difference variables and person-means for dependent variables in Sample 2.

\begin{tabular}{|c|c|c|c|c|c|c|c|c|c|c|c|}
\hline Variable & 2 & 3 & 4 & 5 & 6 & 7 & 8 & 9 & 10 & II & 12 \\
\hline I. Limited willpower theory & -.21 & -.21 & .21 & .18 & .22 & .23 & -.05 & -.02 & -.02 & .14 & -.00 \\
\hline 2. Trait self-control & & .19 & -.11 & .01 & -.12 & -.15 & .07 & -.01 & .23 & -.13 & .03 \\
\hline 3. Morningness chronotype & & & -.19 & -.02 & -.02 & .06 & -.05 & .22 & .26 & .05 & .15 \\
\hline 4. Depression & & & & -.04 & .33 & .29 & -.02 & -.04 & -.06 & -.01 & .11 \\
\hline 5. BMI & & & & & .15 & -.16 & -.17 & .02 & .27 & .00 & .08 \\
\hline 6. Mean subjective fatigue & & & & & & -.78 & -.17 & -.12 & -.19 & -.03 & -.09 \\
\hline 7. Mean subjective affect & & & & & & & -.06 & -.11 & -.22 & -.01 & -.10 \\
\hline 8. Mean low-intensity phys. activity (min) & & & & & & & & .33 & .16 & .07 & .08 \\
\hline 9. Mean moderate-intensity phys. activity (min) & & & & & & & & & .46 & .12 & .11 \\
\hline 10. Mean high-intensity phys. activity (binomial) & & & & & & & & & & .22 & .15 \\
\hline II. Mean snacks consumed & & & & & & & & & & & .40 \\
\hline 12. Mean fruits and vegetables consumed & & & & & & & & & & & \\
\hline
\end{tabular}

Note. Means were calculated for each person, unweighted, regardless of time-of-day. Correlations above $|r=.16|$ are significant at $p<.05$, and correlations above $|r=.21|$ are significant at $p<.01$.

Sample 1

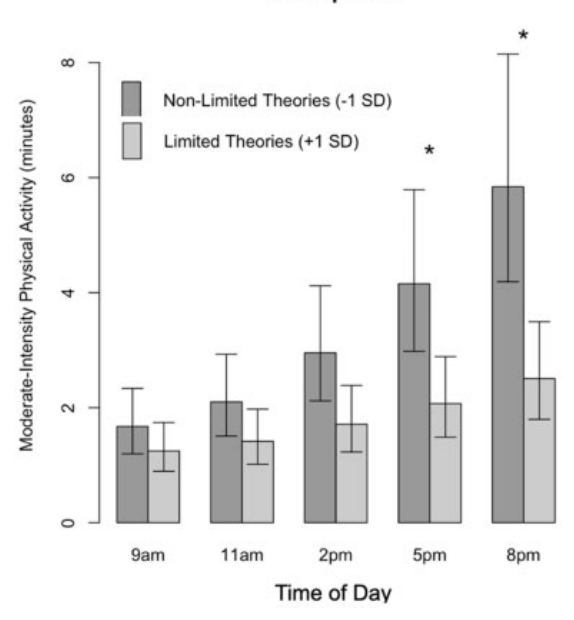

Sample 2

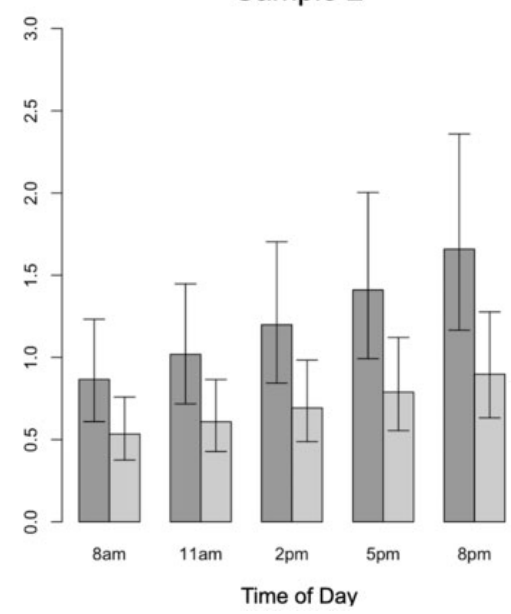

Figure I. Moderate-intensity physical activity reported across the day for more and less limited willpower theorists. Times-of-day are presented in bins for illustrative purposes; analyses were all conducted with time-of-day as a continuous variable. Error bars show the standard errors for willpower theory at that time-of-day. For simple effects, ${ }^{*} p<.05$.

$B=0.06, S E=0.01, z=5.15, p<.001)$. Controlling for age, there were again no significant main effects of willpower theory on physical activity (low $B=-0.15, \quad S E=0.26, \quad z=0.59, \quad p=.55 ;$ moderate $B=-0.52, \quad S E=0.37, \quad z=1.41, \quad p=.16 ; \quad$ high $B=-0.16, S E=0.17, z=0.89, p=.37)$.

As in Sample 1, levels of low-intensity physical activity again increased differently across the course of the day depending on the participant's willpower theories; those holding more nonlimited theories reporting steeper increases in low-intensity activity compared to those who held more limited theories (interaction $\quad B=-0.009, \quad S E=0.002, \quad z=5.14$, $p<.001$, only controlling for age). This directly replicated the finding from Sample 1. However, in this sample willpower theory did not moderate the effect of time-of-day on moderate-intensity activity before controlling for other dispositional traits $(B=-0.002$, $S E=0.004, z=0.62, \quad p=.53)$. Willpower theories again did not significantly moderate the likelihood of participants engaging in high-intensity exercise at different times of day $(B=-0.01, S E=0.02, z=0.60$, $p=.55)$.

After controlling for moderations by chronotype, trait self-control, and trait-depression, willpower theory moderated the effects of time-of-day on both low- and moderate-intensity physical activity (Table 3), replicating Sample 1. Chronotype and trait self-control also simultaneously moderated time-of-day effects on both low- and moderateintensity physical intensity, and depression moderated low-intensity physical activity (Table 3 ).

\section{Snacking across the day}

Sample 1. Snacking generally increased significantly over the course of the day $(B=0.19, S E=0.008$, $z=25.30, p<.001$ ), but this was especially true for 
Table 3. Simultaneous moderations of time-of-day effects by four individual difference measures in Sample 2.

\begin{tabular}{|c|c|c|c|c|c|c|}
\hline & \multirow[b]{2}{*}{ Trait measure } & \multirow{2}{*}{$\begin{array}{l}\text { Time-of-day } \\
\text { interaction } \\
\text { z-score }\end{array}$} & \multicolumn{2}{|c|}{ Simple effect of trait at 8 a.m. } & \multicolumn{2}{|c|}{ Simple effect of trait at 8 p.m. } \\
\hline & & & $B(S E)$ & z-score & $B(S E)$ & z-score \\
\hline \multirow{4}{*}{$\begin{array}{l}\text { Low intensity } \\
\text { physical act. }\end{array}$} & Limited willpower theory & $7.40 * * *$ & $-0.06(0.22)$ & 0.67 & $-0.23(0.22)$ & 1.07 \\
\hline & Trait self-control & $5.61 * * *$ & $0.33(0.44)$ & 1.07 & $0.61(0.44)$ & 1.40 \\
\hline & Morningness chronotype & $21.23 * * *$ & $0.00(0.04)$ & 1.16 & $-0.08(0.04)^{*}$ & 2.32 \\
\hline & Depression & $4.47 * * *$ & $-0.00(0.01)$ & 0.14 & $0.01(0.01)$ & 0.37 \\
\hline \multirow{4}{*}{$\begin{array}{l}\text { Mod. intense. } \\
\text { physical act. }\end{array}$} & Limited willpower theory & $10.30 * * *$ & $-0.18(0.32)$ & 0.55 & $-0.66(0.32)^{*}$ & 2.06 \\
\hline & Trait self-control & $14.95 * * *$ & $0.66(0.64)$ & 1.03 & $-0.54(0.64)$ & 0.84 \\
\hline & Morningness chronotype & $5.25 * * *$ & $0.10(0.05)$ & 1.84 & $0.07(0.05)$ & 1.25 \\
\hline & Depression & 0.25 & - & - & - & - \\
\hline \multirow[t]{4}{*}{ Snacking } & Limited willpower theory & $3.80 * * *$ & $0.22(0.14)$ & 1.61 & $0.04(0.13)$ & 0.29 \\
\hline & Trait self-control & 0.95 & - & - & - & - \\
\hline & Morningness chronotype & $2.38^{*}$ & $0.003(0.03)$ & 0.14 & $-0.01(0.02)$ & 0.40 \\
\hline & Depression & 0.48 & - & - & - & - \\
\hline
\end{tabular}

$*_{p}<.05 . * * p<.01 . * * * p<.001$.
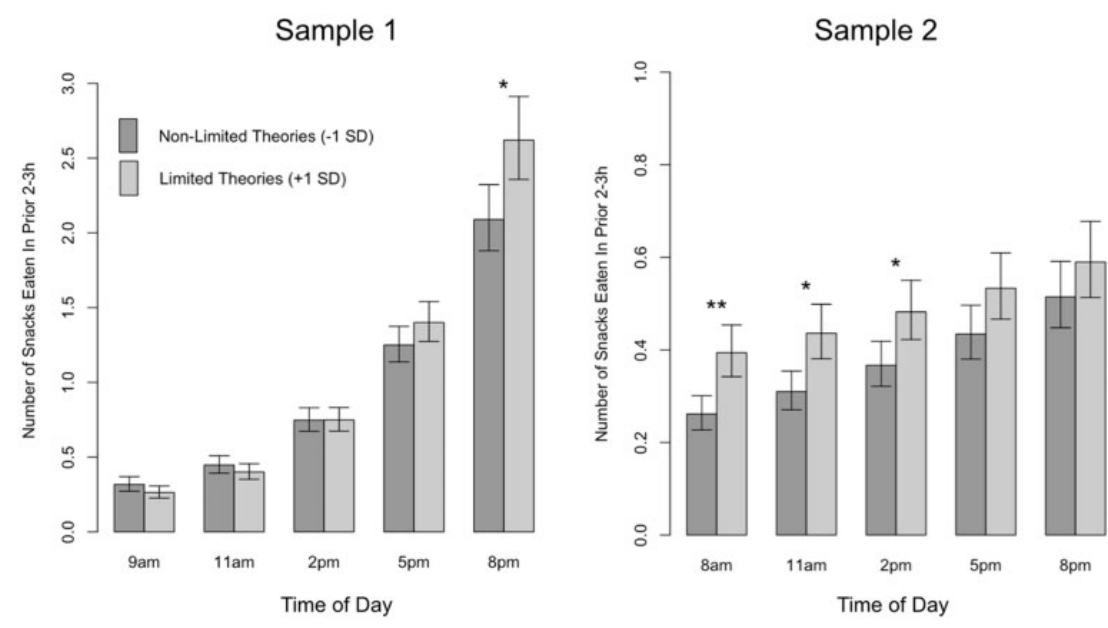

Figure 2. Number of snacks reported across the day for more and less limited willpower theorists. Analyses were all conducted with time-of-day as a continuous variable. Error bars show the standard errors for willpower theory at that time-of-day. For simple effects, $*_{p}<.05 . * * p<.01$. ***p $<.001$.

those with more limited willpower theories (Figure 2); the interaction between willpower theory and time-ofday was significant $(B=0.03, S E=0.01, z=2.50$, $p=.013)$. For example, controlling for age, a limited willpower theorist (at $1 S D$ above the mean) would report recently eating an estimate of 2.04 more snacks at 8 p.m. compared to at 10 a.m. $(S E=0.12$, $z=19.61, p<.001)$. A nonlimited willpower theorist (at $1 S D$ below the mean) would eat an estimated 1.59 more snacks at 8 p.m. compared to 10 a.m. $(S E=0.11, z=16.18, p<.001)$. There was no significant main effect of willpower theories $(B=0.02$, $S E=0.08, z=0.30, p=.77)$ nor of age $(B=0.0009$, $S E=0.005, z=0.19, p=.85)$.

Replication Sample 2. As in Sample 1, rates of snacking significantly increased as the day progressed $(B=0.04, S E=0.004, z=11.52, p<.001)$. In this sample, a more limited willpower theory was associated with more snacking overall (i.e., at the day's mid- point; main effect $B=0.24, \quad S E=0.11, \quad z=2.12$, $p=.034)$. The change in snacking rates across the day again depended on willpower theory (interaction $B=-0.02, \mathrm{SE}=0.006, z=3.07, p=.002$ ), but not in the same way as in Sample 1. Unlike our hypothesis and findings from Sample 1, those with more limited theories of willpower snacked relatively more than those with more nonlimited willpower theories earlier in the day (Figure 2). This unexpected interaction did not change after controlling for chronotype, depression, trait self-control, and the time-of-day interactions with these three variables (many of which were significant; see Table 3).

One possible reason for the unexpected direction of this effect is that the participants in Sample 2 generally had more prominent academic goals instead of goals to avoid snacking. To examine whether snackavoidance goals might have contributed to this unexpected direction of the moderation, we conducted an 
exploratory analysis of a possible three-way interaction between time-of-day, willpower theory, and snack intention (reported during the first survey of the day only).

The three-way interaction (between time, willpower theory, and snack intention) did significantly predict snacks eaten $(B=0.008, S E=0.003, z=2.45$, $p=.014)$. On days when participants had only a weak intention to avoid snacks ( 2 on a 1-10 scale, 1st quantile), participants with more limited willpower theories consumed more snacks in the morning than participants with more nonlimited theories (two-way interaction $B=-0.03, \quad S E=0.009$, $z=3.65, p<0.001)$. On days when participants had a greater intention to avoid snacks ( 7 on the $1-10$ scale, 3rd quantile), there was no significant interaction between willpower theory and time-of-day $(B=-0.011, S E=0.008, z=1.31, p=.191)$. Instead, those with more limited willpower theories were marginally more likely to snack more overall, and the sample in general was marginally more likely to snack later in the day. In other words, the unexpected interaction between willpower theories and time-ofday (where a more limited theory was associated with less healthy behaviour in the mornings, particularly) was primarily driven by days when participants had weak intentions to avoid eating snacks.

\section{Fruit and vegetable intake across the day}

Finally, reported consumption of fruit and vegetables increased throughout the day $(B=0.07, S E=0.007$, $z=10.44, p<.001)$, but the degree of this increase did not vary based on willpower theories (interaction $B=0.01, S E=0.01, z=0.56, p=.34)$. There was a marginal relationship between willpower theories and fruit and vegetables consumed, where a more limited willpower theory was associated with the consumption of somewhat fewer fruits and vegetables $(B=-0.16, S E=0.09, z=1.79, p=.07)$. However, this association was not significant after controlling for age $(B=-0.14, S E=0.10, z=1.52, p=.129)$. Sample 2 showed the same null patterns (see Supplemental Materials S3).

\section{Health intentions}

Analyses of intentions across the course of the day were conducted only on Sample 1, because Sample 2 participants only reported on their intentions once per day.

Intentions to be physically active were significantly affected by time of day and by willpower theories, and these factors interacted. Overall, a more limited willpower theory was associated with weaker intentions to be active, and intentions to be active generally declined across the day. While even nonlimited willpower theorists' intentions to be active decreased across the day (at $-1 S D, B=-0.085, S E=0.005$, $z=16.63, p<.001$ ), those with a more limited willpower theory had more steeply weakening intentions across the day $(+1 S D, B=-0.113, S E=0.006$, $z=20.29, p<.001)$.

While participants generally reported stronger intentions to avoid snacking as the day progressed, this effect was again significantly moderated by willpower theory (Table 4). Across the day, those holding more nonlimited willpower theories increased their intentions to avoid snacks (at $-1 S D, B=0.073$, $S E=0.023, p=.002)$, but those holding more limited theories had stable intentions across the day $($ at +1 $S D, B=0.003, S E=0.022, p=.90)$.

Associations between intentions and later behaviour. We conducted lagged analyses to confirm that withinparticipant intentions in each domain predicted the actual reported behaviour at the following completed survey (on the same day). We also tested whether the strength of the association between intentions and subsequent behaviours varied according to willpower theory.

Low-intensity and moderate-intensity physical activity were each predicted by intentions to be physically active $\left(B_{\text {low }}=0.10, \quad S E=0.004, \quad z=26.01\right.$, $\left.p<.001 ; \quad B_{\text {mod }}=0.09, \quad S E=0.007, \quad z=13.22\right)$, and these relationships were each moderated by willpower theory (interaction $B_{\text {low }}=0.02, S E=0.005, z=3.68$, $p<.001 ; B_{\text {low }}=0.04, S E=0.006, z=6.63, p<.001$; two-level models). Unexpectedly, those with nonlimited willpower theories (i.e., at $-1 S D$ ) had somewhat weaker associations between their intentions and their subsequent actual activity levels (e.g., $B_{\text {low }}=0.09$, $S E=0.005, z=16.77, p<.001)$ and more limited willpower theorists (at $+1 S D)$ had slightly stronger associations $\left(B_{\text {low }}=0.11, S E=0.005, z=24.56, p<.001\right)$. Actual snacking was predicted by prior intention to avoid snacking $(B=-0.06, \quad S E=0.01, \quad z=4.00$, $p<.001$ ), but this was not moderated by willpower theory (interaction $B=0.008, S E=0.02, \quad z=0.31$, $p=.76)$. We were unable to test whether these associations further varied by time-of-day or when nested within-day, due to insufficient observations. Across behaviours, there was no evidence for the hypothesis that those with more limited willpower theorists were any less likely to adhere to their intentions.

\section{Subjective states}

Sample 1. People generally felt more fatigued, less self-efficacious, and less happy as the day progressed (Table 4). All changes in subjective state across the day were significantly larger for those with more limited theories of willpower. There were also significant main effects of willpower theory; holding a more limited willpower theory was associated with more fatigue, less happiness, and less self-efficacy on average (i.e., at day's mid-point).

Replication Sample 2. Replicating Sample 1, people generally felt more fatigued as the day progressed 
Table 4. Subjective states and intentions across time-of-day and moderations of these time effects.

\begin{tabular}{|c|c|c|c|c|}
\hline & \multicolumn{2}{|l|}{ Sample I } & \multicolumn{2}{|l|}{ Sample 2} \\
\hline & $B(S E)$ & $r$ & $B(S E)$ & $r$ \\
\hline \multicolumn{5}{|l|}{ Fatigue } \\
\hline Time of day & $0.19(0.02)^{* * *}$ & .23 & $0.09(0.002)^{* * *}$ & .42 \\
\hline Lim. willpower theory & $-1.71(0.33)^{* * *}$ & .38 & $0.16(0.08)^{*}$ & .19 \\
\hline Trait self-control & - & - & $-0.04(0.15)$ & .02 \\
\hline Morning chronotype & - & - & $0.04(0.01)^{* *}$ & .24 \\
\hline Depression & - & - & $0.03(0.01)^{* * * *}$ & .53 \\
\hline Time $\times$ WP theory & $0.11(0.03)^{* *}$ & .08 & $0.00(0.004)$ & .01 \\
\hline Time $\times$ Self-control & - & - & $-0.01(0.01)$ & .02 \\
\hline Time $\times$ Chronotype & - & - & $0.01(0.00 \mathrm{I})^{* * *}$ & .15 \\
\hline Time $\times$ Depression & - & - & $0.00(0.00)$ & .01 \\
\hline \multicolumn{5}{|l|}{ Subjective affect } \\
\hline Time of day & $-0.05(0.02)^{*}$ & .06 & $0.004(0.003)$ & .02 \\
\hline Lim. willpower theory & $-1.35(0.51)^{*}$ & .21 & $-0.15(0.10)$ & .13 \\
\hline Trait self-control & - & - & $0.03(0.20)$ & .01 \\
\hline Chronotype & - & - & $-0.03(0.02)$ & .14 \\
\hline Depression & - & - & $-0.05(0.01)^{* * *}$ & .54 \\
\hline Time $\times$ WP theory & $-0.11(0.04)^{*}$ & .07 & $0.01(0.004)$ & .02 \\
\hline Time $\times$ Self-control & - & - & $-0.01(0.01)$ & .01 \\
\hline Time $\times$ Chronotype & - & - & $0.001(0.001)$ & .02 \\
\hline Time $\times$ Depression & - & - & $0.000(0.000)$ & .01 \\
\hline \multicolumn{5}{|l|}{ Self-efficacy } \\
\hline Time of day & $-0.08(0.0 \mathrm{I})^{* * *}$ & .22 & - & - \\
\hline Lim. willpower theory & $-0.30(0.14)^{*}$ & .16 & - & - \\
\hline Time $\times$ WP theory & $-0.03(0.02)^{*}$ & .05 & - & - \\
\hline \multicolumn{5}{|l|}{ Avoiding snacking intentions } \\
\hline Time of day & $0.04(0.02)^{*}$ & .06 & - & - \\
\hline Lim. willpower theory & $0.34(0.31)$ & .08 & - & - \\
\hline Time $\times$ WP theory & $-0.06(0.03)^{*}$ & .07 & - & - \\
\hline \multicolumn{5}{|l|}{ Physical activity intentions ${ }^{\mathrm{a}}$} \\
\hline Time of day & $-0.10(0.004)^{* * * *}$ & .03 & - & - \\
\hline Lim. willpower theory & $-0.19(0.06)^{* *}$ & .05 & - & - \\
\hline Time $\times$ WP theory & $-0.03(0.007)^{* * * *}$ & .01 & - & - \\
\hline
\end{tabular}

Note. All trait variables and interactions were tested as simultaneous predictors. Presented models did not include age as a covariate, although including age did not substantially change any results or effect sizes.

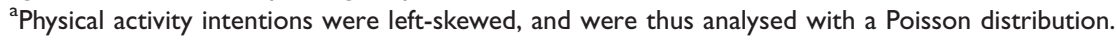

$* p<.05 . * * p<.01$. *** $p<.001$.

(Table 4). Affect, however, did not change across the course of the day.

Participants with more limited willpower theories again tended to report lower subjective affect and more subjective fatigue overall $\left(B_{\text {affect }}=-0.28\right.$, $S E=0.10, \quad t(149)=-2.66, \quad p=.009, \quad r=.21$; $B_{\text {fatigue }}=0.22, \quad S E=0.08, \quad t(149)=2.86, \quad p=.005$, $r=.23$ ). Unlike in Sample 1, where willpower theory affected levels of subjective fatigue most in the evening, in this sample, willpower theory predicted subjective fatigue most in the morning. Participants in general became more fatigued across the course of the day, but more limited theorists started out more fatigued $\quad(B=0.009, \quad S E=0.003, \quad t(8009)=2.84$, $p=.004, r=.03)$ and showed less steep increases in fatigue across the day $(B=0.082$ rather than $B=0.091, \quad S E=0.007)$. Subjective affect did not change across time any differently depending on willpower theory (interaction $B=0.004, S E=0.004, t$ $(7920)=1.04, p=.296, r=.01)$.
After accounting for the related individual difference variables - trait depression, chronotype and trait-self-control - willpower theories no longer significantly affected subjective affect, either overall or at particular times-of-day (Table 4). After accounting for other variables, a more limited willpower theory was still associated with more fatigue, regardless of time-of-day.

Because willpower theory did not predict changes in self-reported affect or fatigue across the course of the day, we did not consider self-reported affect or fatigue as potential mediators of the behavioural effects in Sample 2.

\section{Mediation models (Sample I)}

Selecting mediators. We were next interested in exploring potential mediators to explain the moderation of time-of-day by willpower theory (Figure 3(a)). In Sample 1, fatigue, affect, self-efficacy and health 


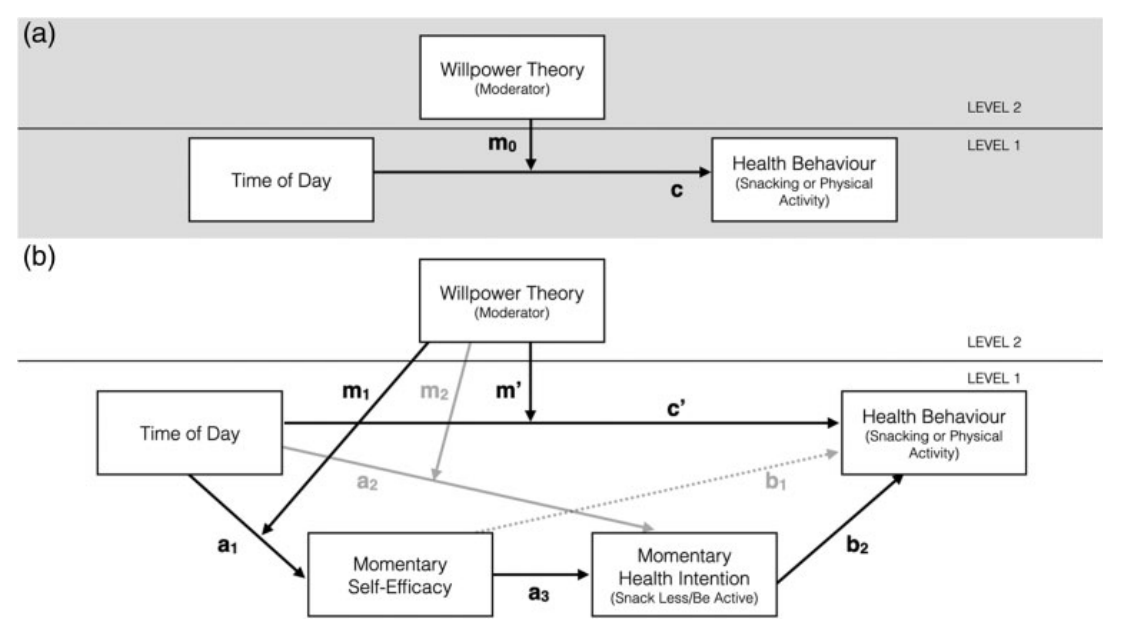

Figure 3. Time of day moderation and the serial mediation model tested to explain the moderation. Panel (a) shows the original moderation $\left(m_{0}\right)$. Panel $(b)$ shows the tested double mediation model, with the proposed pathway $a_{1}-a_{3}-b_{2}$ in black, and alternative single-mediation models in grey. Dashed line is not statistically significant. Main effects of willpower theory, not shown, were included in the models whenever moderations of willpower theory were tested. Coefficients and standard errors for each pathway and confidence intervals for indirect effects are available in Table 5. Age was included as a covariate for all pathways. Pathways bl, b2, c', and $\mathrm{m}$ ' are lagged across time (i.e., where self-efficacy or health intention predicts behaviour reported at the subsequent experiencesampling survey on the same day).

intentions were all potential mediators of the willpower theory by time-of-day interaction, since all measures varied differently across time of day according to willpower theory. We chose the best mediator by running three lagged-effect models predicting our dependent variables (low-intensity physical activity, moderate-intensity physical activity, and snacking), with each of the four candidate mediators (self-efficacy, affect, fatigue, and intentions; lagged from the prior survey) as simultaneous predictors.

Out of the four candidate mediators, low-intensity physical activity was most strongly predicted by prior intentions to be active as reported at the prior survey $(B=0.10, S E=0.004, z=27.10, p<.001)$, although each of prior self-efficacy, prior fatigue, and prior affect were also significant simultaneous predictors of later physical activity. Likewise, moderateintensity physical activity was most strongly related to prior intentions to be active $(B=0.11, S E=0.005$, $z=25.16, p<.001$ ), while also being simultaneously predicted by prior self-efficacy, fatigue and affect. We further wondered why people were setting more or less ambitious intentions for themselves, and whether these explicit intentions may have been related to one's subjective state. Indeed, these intentions to be physically active were themselves most strongly predicted by state self-efficacy $(B=0.11, S E=0.01$, $z=8.54, p<.001$ ), while also being related to one's momentary affect and fatigue $\left(B_{\text {affect }}=0.01\right.$, $S E=0.005, \quad z=2.51, \quad p=.012 ; \quad B_{\text {fatigue }}=-0.03$, $S E=0.005, z=4.72, p<.001)$.

Snacking was most strongly predicted by prior snacking intentions $(B=-0.06, S E=0.01, z=4.42$, $p<.001)$; when prior snacking intention was a predictor, neither affect nor self-efficacy added any additional predictive value $(p s>.55)$ and prior fatigue was a somewhat weaker predictor $(B=0.03$, $S E=0.01, z=2.55, p=.011)$. Like intentions to be physically active, intentions to avoid snacking were also significantly predicted by momentary selfefficacy (Table 5). Interestingly, intentions to avoid snacking were not related to momentary fluctuations in affect nor fatigue $\left(B_{\text {affect }}=-0.005, S E=0.02, t\right.$ $(1643)=0.24, p=.811 ; \quad B_{\text {fatigue }}=0.02, S E=0.02, t$ $(1616)=0.83, p=.407)$.

Thus, for each of mild- and moderate-physical activity and for snacking, our data suggested that these patterns of health-related behaviours may be best explained by prior intentions, which were themselves explained by momentary self-efficacy. Because all of self-efficacy, intentions, and the ultimate behaviours changed across the course of the day differently depending on one's willpower theory, we tested whether the original moderation (Figure 3(a)) could be explained by changing self-efficacy and intentions (Figure 3(b)).

Testing for indirect effects and mediation. After determining that self-efficacy and intentions were the most predictive mediators, we tested the proposed moderated double mediation model shown in Figure 3(b). Indirect effects were calculated by bootstrapping 10,000 simulations with the Monte Carlo method (Preacher \& Selig, 2010). We were interested in whether the original moderation $\left(\mathrm{m}_{0}\right.$, Figure $\left.3(\mathrm{a})\right)$ of time-of-day effects by willpower theory would be explained by the indirect mediation pathway through self-efficacy and intentions (black pathways, $\mathrm{a}_{1}-\mathrm{a}_{3}-\mathrm{b}_{2}$ in Figure 3(b)), resulting in a reduction of the remaining direct moderation effect ( $m$ ' in Figure 3(b)). We also tested single-mediator models (Table 5; light grey 
Table 5. Coefficients and standard errors for the double mediation model (Figure 3).

\begin{tabular}{|c|c|c|c|c|}
\hline Model pathway & Figure label & $\begin{array}{l}\text { Low-intensity } \\
\text { activityB (SE) }\end{array}$ & $\begin{array}{l}\text { Mod-intensity } \\
\text { activityB (SE) }\end{array}$ & SnackingB (SE) \\
\hline Willpower theory moderation on behaviour & $\mathrm{m}_{0}$ & $-0.02(0.004)^{* * *}$ & $-0.03(0.005)^{* * *}$ & $0.03(0.01)^{*}$ \\
\hline Willpower theory moderation on self-efficacy & $\mathrm{m}_{\mathrm{l}}$ & $-0.03(0.01)^{*}$ & $-0.03(0.01)^{*}$ & $-0.03(0.01)^{*}$ \\
\hline Willpower theory moderation on intention & $\mathrm{m}_{2}$ & $-0.02(0.007)^{* * *}$ & $-0.02(0.007)^{* * *}$ & $-0.06(0.03)^{*}$ \\
\hline Time on self-efficacy & $a_{1}$ & $-0.08(0.01)^{* * * *}$ & $-0.08(0.01)^{* * *}$ & $-0.08(0.01)^{* * *}$ \\
\hline Time on intention & $a_{2}$ & $-0.10(0.004) * * *$ & $-0.10(0.004) * * *$ & $0.05(0.02)^{* *}$ \\
\hline Self-efficacy on intention & $a_{3}$ & $0.06(0.01)^{* * * * *}$ & $0.06(0.01)^{* * * *}$ & $0.14(0.05)^{* *}$ \\
\hline Self-efficacy on behaviour ${ }^{a}$ & $b_{1}$ & $0.01(0.01)$ & $0.05(0.02)^{* *}$ & $-0.02(0.03)$ \\
\hline Intention on behaviour ${ }^{\mathrm{a}}$ & $b_{2}$ & $0.12(0.004)^{* * *}$ & $0.15(0.005)^{* * *}$ & $-0.06(0.0 \mathrm{l})^{* * *}$ \\
\hline Time on behaviour (remaining) $^{\mathrm{a}}$ & $c^{\prime}$ & $0.09(0.004)^{* * * *}$ & $0.14(0.004)^{* * *}$ & $0.24(0.01)^{* * *}$ \\
\hline $\begin{array}{l}\text { Willpower theory moderation } \\
\text { on behaviour (remaining) }\end{array}$ & m' & $0.003(0.005)$ & $-0.04(0.007)^{* * *}$ & $0.04(0.02)^{*}$ \\
\hline Indirect effects & & $95 \% \mathrm{Cl}$ & $95 \% \mathrm{Cl}$ & $95 \% \mathrm{Cl}$ \\
\hline $\begin{array}{l}\text { Single mediator (self-efficacy) of } \\
\text { the moderation }\end{array}$ & $m_{1} b_{1}$ & {$[-0.001,0.0003]$} & {$[-0.004,0.0001]$} & {$[-0.003,0.00 I]$} \\
\hline Single mediator (intention) of the moderation & $\mathrm{m}_{2} \mathrm{~b}_{2}$ & {$[-0.005,-0.001]^{*}$} & {$[-0.006,-0.002]^{*}$} & {$[-0.005,0.015]$} \\
\hline Double mediation of the moderation & $m_{1} a_{3} b_{2}$ & {$[-0.0005,-0.00002]^{*}$} & {$[-0.0006,-0.00002]^{*}$} & {$[0.000014,0.0007]^{*}$} \\
\hline
\end{tabular}

arrows in Figure 3), with only intentions or only selfefficacy as the single mediator.

When the double mediation model was conducted for the dependent variable of low-intensity physical activity, we found that the double mediation indirect pathway was significant $(95 \%$ CI $[-0.0005$, $-0.00002])$. The remaining direct moderation effect was also reduced (from $B=-0.02$ to $B=0.003$ ), which suggests that the indirect mediation pathway (through self-efficacy and health intentions) seems to largely explain the original moderation effect. When examining moderate-intensity physical activity, the double mediation pathway for moderate-intensity physical activity was again a significant indirect effect, although this indirect effect did not reduce the magnitude of the original $\left(\mathrm{m}_{0}\right)$ moderation (Table 5). When we conducted the same model a third time, examining the dependent variable of snacking, the indirect effect of the double mediation pathway was again significant $(95 \%$ CI $[0.000014,0.0007])$. In this case, the remaining direct moderation of time-of-day by willpower theory on snacking $\left(\mathrm{m}^{\prime}\right)$ was again not reduced in magnitude (Table 5).

Analyses for all three dependent variables support the existence of these indirect effects - where willpower theory affects time-of-day changes on self-efficacy, intentions to avoid snacking and ultimately health-behaviours themselves. However, these indirect pathways only reduced the magnitude of the original moderations for low-intensity physical activity, but not for moderate-intensity physical activity or snacking (Rucker et al., 2011). Thus, the doublemediation process shown in Figure 3 seems to largely explain the observed patterns of low-intensity physical activity for more and less limited willpower theorists across time, but willpower theory is still associated with other behaviour changes across the course of the day that are not explained by this indirect pathway of changing self-efficacy and intentions.

\section{General discussion}

While different times of day are indeed associated with different choices and intentions about food and physical activity, these daily fluctuations in selfregulation outcomes seem to vary depending on people's beliefs about the nature of willpower. People who hold theories of willpower as more limited reported relatively weaker health intentions and less goal-congruent behaviours as the day progresses, compared to their nonlimited theorist counterparts.

\section{Willpower theories and physical activity}

In both samples, participants' willpower theories moderated how their levels of low-intensity physical activity and moderate-intensity physical activity changed across the day. Compared to participants who held more nonlimited willpower theories, those with more limited theories were relatively less likely to be physically active later in the day (reporting fewer minutes of low-intensity and moderate-intensity physical activity). These effects of willpower theory were independent of moderations by chronotype, trait selfcontrol and depression symptoms. The reverse of this finding is that those with limited willpower beliefs were more likely to report sedentary behaviour, particularly later in the day. These findings are consistent with experimental results showing that limited 
willpower theorists sit longer in chairs after exerting self-control (Job, Bernecker, et al., 2015). In Study 1, limited willpower beliefs were also associated with weaker intentions to be physically active, particularly later in the day. In lab settings and in the real world, for both community participants with health goals and students with academic goals, those with more limited willpower theories seem to be less physically active, especially in the evenings.

Notably, willpower theories were not related to patterns of high-intensity physical activity in either sample, though the occurrence of such physical activity was relatively rare. While the other behaviours snacking and low/moderate physical activity - are likely to occur multiple times throughout the day, most people only engage in high-intensity physical activity (e.g., sports or exercise) up to once per day. Due to this difference, high-intensity physical activity may be less susceptible to changes in self-control fluctuations across the day, particularly since the timing of these activities may often be externally driven (e.g., scheduled sports games or gym classes), habitual or planned ahead of time. Limited willpower theorists who are poor at self-regulation may, in fact, be more like to plan their exercise for later in the day (Delose et al., 2015), despite holding weaker intentions to be physically active and typically being more sedentary during these later hours. Future research should further explore how the processes motivating organic daily physical activity (e.g., walking) differ from the processes motivating more intensive, perhaps formally scheduled exercises.

\section{Willpower theories, snacking and the importance of goal-relevance}

While the results for physical activity levels were consistent between both samples, the results for snacking diverged between the community sample with health goals (Sample 1) and the student sample with academic goals (Sample 2). For community participants in Sample 1, willpower theories predicted snacking patterns that paralleled the physical activity patterns. Particularly later in the day, more limited willpower theorists less strongly intended to avoid snacking, and ultimately snacked more. For participants with health goals, then, endorsing a more limited theory of willpower was related to less health-goal adherence more snacking - later in the day.

The relationship between willpower theories and snacking was different in Sample 2, where students were generally less focused on health goals. In this sample, a limited willpower theory predicted more snacking overall, as a main effect, and the effect of limited willpower theory was larger in the mornings rather than in the evenings. The unexpected interaction was driven by participants who did not intend to avoid snacking. From the differing results in Sample 1 and Sample 2, it is clear that believing willpower is limited does not always result in higher susceptibility to late-night snacking. For students with no intention to avoid snacking, in fact, eating a snack likely does not represent a "self-control failure" at all (Milyavskaya et al., 2019). Although some exploratory analyses suggest that the differences in health-goals between samples partially explain the differing patterns in snacking behaviours, future research is needed to discover the specific conditions under which a limited theory is associated with more snacking overall or just more snacking in the evening.

\section{Possible mechanisms of willpower theories}

We hypothesized that willpower theories could affect health behaviours through a few possible mechanisms, including by reducing people's ability to adhere to their set intentions, by affecting feelings of momentary self-efficacy and intention setting, or affecting people's subjective affect and sense of fatigue.

Those endorsing more limited willpower theories did not seem any less able to fulfil their intentions, relative to those endorsing more nonlimited theories. Willpower theory did not significantly moderate the association between intention to avoid snacking and actual snacking; in fact, more limited theorists had slightly stronger relationships between their physical activity intentions and actual physical activity at the subsequent survey - perhaps reflecting limited theorists having a more realistic view of themselves and nonlimited theorists being unrealistically optimistic. However, we were only able to test this hypothesis in Sample 1, which had a limited number of observations from days where participants completed multiple surveys. Thus, this test was likely underpowered, and the results should be interpreted with caution. Preliminarily, however, this evidence is inconsistent with the hypothesis of reduced self-control strength, where limited theorists are less able to enact their intentions.

Analyses from Sample 1 instead suggested that willpower theory affected both self-efficacy and intention-setting. A more limited willpower theory was associated with less momentary self-efficacy throughout the day, which was in turn associated with progressively weakened intentions to be physically active and avoid snacking. In contrast, selfefficacy and intentions of more nonlimited theorists became stronger over the course of the day, predicting an increase in health-goal consistent behaviours. It is noteworthy that people's global state (overall selfefficacy) predicted more narrow domain-specific intentions, perhaps through influencing people's feelings of domain-specific self-efficacy (not measured).

This process, of limited theorists feeling relatively less self-efficacious throughout the day and setting lower expectations for themselves, could happen consciously or subconsciously. More limited theorists 
might be aware that they often become tired (and more sedentary) in the evening, and may lower their self-expectations accordingly. These low expectations might then become a self-fulfilling prophesy, and may even reinforce one's theory of willpower. This pattern of intention-setting in people's daily life is consistent with prior experimental work finding that people are less inclined to plan when they are depleted (Sjåstad \& Baumeister, 2018). Both intention-setting and planning are similar future-oriented processes, and both may be similarly affected by willpower theories. Of course, the causal directions cannot be determined from this design.

Finally, while believing that willpower is more limited was generally associated with more fatigue and less positive subjective affect (main effects in both samples), fatigue did not consistently accumulate across the day more quickly for those who held a more limited theory - this pattern of moderation was significant in Sample 1, but not Sample 2. Why are limited willpower theories associated with more fatigue overall, even in the morning? Potentially, students with more limited willpower theorists may still be feeling depletion-like effects from their efforts during the previous day (Bernecker \& Job, 2015b) or may have procrastinated going to bed the night earlier, resulting in having had less sleep (Bernecker $\&$ Job, 2020). Subjective reports of fatigue might conflate feelings of sleepiness with feelings of mental fatigue. Even among Sample 1, which did find more limited theorists become particularly fatigued as the day progressed, neither feelings of fatigue nor subjective affect consistently mediated the patterns of health behaviours or intention-setting.

\section{Practical implications}

Fundamentally, these data find that willpower theories are related to both physical activity and snacking, both of which are related to lifelong health outcomes. The varying patterns of diet and exercise found in this study likely contribute to the differences in BMI (Bernecker \& Job, 2015a), and perhaps even the differences in subjective well-being (Bernecker et al., 2017), previously linked to willpower theory. In both samples, the physical activity discrepancy between more limited and more nonlimited willpower theorists in the evenings mirrored the physical activity discrepancy previously found between obese and nonobese individuals (Cooper et al., 2000) and - among the sample of participants trying to improve their nutrition - the time-of-day snacking patterns reported by those who endorsed more limited theories of willpower more closely resemble the eating patterns associated with higher BMI, greater psychological distress and higher overall caloric intake (Colles et al., 2007; de Castro, 2004).

Willpower theories were not the only individual difference to predict these variables - in fact, chronotype was a stronger predictor of low- and moderate-intensity physical activity. Unlike chronotype, however, willpower theories are potentially malleable. Beliefs about willpower can be manipulated in the lab (Job et al., 2010; Klinger et al., 2018), vary across cultures (Savani \& Job, 2017), and with experiences of autonomy (Job et al., 2018; Sieber et al., 2019). Future interventions to modify willpower beliefs could thus apply to the domains of diet and exercise. Willpower beliefs may be a particularly good target for interventions, since they seem to act by influencing feelings of self-efficacy and intentions reflecting expectations of the self - rather than by affecting underlying feelings of fatigue or depletion.

\section{Limitations and future directions}

This research is not without limitations. First, because willpower theories were measured, not manipulated, we cannot say that willpower theories have a causal impact on health behaviours or other outcomes. While Sample 2 suggests that willpower theories are predictive above and beyond related constructs like trait self-control, chronotype and depression, we do not know whether interventions or manipulations to change willpower theories would causally affect health and well-being behaviours. However, given that experimental evidence exists demonstrating both directions of causality - willpower theories affecting experiences (Clarkson et al., 2016; Job et al., 2010; Job, Bernecker, et al., 2015), and experiences affecting willpower theories (Klinger et al., 2018; Sieber et al., 2019) - interventions to encourage nonlimited theories of willpower may be a promising avenue for future research.

Each sample also had its own methodological weakness, although each sample compensated for limitations in the other. Sample 1 had low survey completion rates (although completion rates were not associated with willpower theory or other predictors; see Supplemental Materials S1.4) and did not include related individual differences measures. While Sample 2 had excellent survey completion and included related covariates, most of the student participants did not have health goals, and the study did not include variables of potential mediators (like self-efficacy and intentions). Because of our two sample approach, results that were consistent across samples - for instance, effects on low-intensity physical activity - are more likely to be robust and generalizable. Findings from single samples should be treated as exploratory until replicated in future research.

Next, both of our samples consisted of Western, predominantly female participants. Other research has often found gender differences in physical activity levels (Hamrik et al., 2014), attitudes towards snacking (Grogan et al., 1997), and motivations for both healthy eating and physical activity (Heaven et al., 
2001; Lauderdale et al., 2015). Generally, women are more likely to want to increase their physical activity or change their eating habits to meet societal expectations or to change their outward appearance. These external (or introjected) motivations are more likely to result in snacking and physical activity being experienced as effortful self-control conflicts (Werner et al., 2016), and thus may be more likely to be affected by willpower theories. In populations where physical activity is not seen as a self-control conflict, or where baseline levels and types of physical activity differ, willpower theories may not affect time-of-day effects in the same way. Indeed, exploratory moderation analyses suggest that the men in these studies $(n=27$ in each sample) did not show the same patterns as the women, although the small number of men limits both the statistical power and generalizability of these three-way interactions. Like much research on health goals, our results may be specific to women. More broadly, as observed across the two samples examined here, different populations can have substantially different goals and lifestyles, which can change how willpower theories and other individual differences predict self-regulation outcomes.

Finally, this data relied on self-report. Although the experience-sampling method meant that participants only recalled behaviours from the previous 2 to $3 \mathrm{~h}$, there is still the potential for memory errors or self-report biases.

\section{Conclusions}

Increases in snacking and insufficient physical activity are risk factors for a variety of health conditions, and are ultimately related to lower quality of life and increased mortality (Housman \& Dorman, 2005). This study is the first to demonstrate that individuals who believe that willpower is more limited are particularly susceptible to sedentary behaviour later in the day, tend to snack more, and may generally be more susceptible to behaviours inconsistent with their health-goals as the day progresses. These differing behavioural patterns may be because those who believe willpower is more limited feel less selfefficacious and hold less ambitious intentions for themselves later in the day. Encouraging beliefs in nonlimited willpower may be one way to improve health behaviours.

\section{Data accessibility statement}

가 3 The data and materials are permanently and openly accessible at https://osf.io/vyxw7/.

\section{Declaration of conflicting interests}

The author(s) declared no potential conflicts of interest with respect to the research, authorship, and/or publication of this article.

\section{Funding}

This research was supported by a grant of the Swiss National Science Foundation (No. 140991) to Jutta Mata and Roselind Lieb, and by funding from the Social Sciences and Humanities Research Council of Canada to Zoë Francis.

\section{Supplemental material}

Supplemental material for this article is available online.

\section{Notes}

1. Between the two weeks of experience-sampling surveys, participants in Sample 1 completed three online modules of one of three different interventions. Only 47 participants returned for the follow-up second week of experience-sampling, and the intervention condition did not significantly affect any measured variable. All available experience-sampling data, from both before and after the interventions, were used for our analyses.

2. It is typically considered best practice to include random slopes (along with random intercepts) for within-subject factors like time-of-day, to avoid inflation of Type I error (Barr, 2013). On the other hand, models with random slopes and intercepts can have reduced statistical power (Matuschek et al., 2017). In Sample 1, models that included random slopes rarely converged, due to lower response rates and fewer degrees of freedom. In Sample 2, we used and reported results from the same analyses as used for Sample 1. However, the number of observations in Sample 2 was sufficient for random slope models to converge (as a two-level model with random slopes and intercepts for each participant, but not typically as a three-level model that considered day). Results of these random slope models often, but not always, paralleled results from the random intercept models.

\section{References}

AbuSabha, R., \& Achterberg, C. (1997). Review of selfefficacy and locus of control for nutrition- and healthrelated behavior. Journal of the American Dietetic Association, 97(10), 1122-1132. https://doi.org/10.1016/ S0002-8223(97)00273-3

Adan, A., \& Almirall, H. (1991). Horne \& Östberg morningness-eveningness questionnaire: A reduced scale. Personality and Individual Differences, 12(3), 241-253. https://doi.org/10.1016/0191-8869(91)90110-W

Adriaanse, M. A., Kroese, F. M., Gillebaart, M., \& De Ridder, D. T. D. (2014). Effortless inhibition: Habit mediates the relation between self-control and unhealthy snack consumption. Frontiers in Psychology, 5, 444. https://doi.org/10.3389/fpsyg.2014.00444

Barr, D. J. (2013). Random effects structure for testing interactions in linear mixed-effects models. Frontiers in Psychology, 4(June), 3-4. https://doi.org/10.3389/fpsyg. 2013.00328

Bates, D., Maechler, M., Bolker, B., \& Walker, S. (2015). Fitting linear mixed-effects models using lme4. Journal of Statistical Software, 67(1), 1-48. doi:10.18637/jss. v067.i01. 
Baumeister, R. F., \& Heatherton, T. F. (1996). Self-regulation failure: An overview. Psychological Inquiry, 7(1), 1-15. https://doi.org/10.1207/s15327965pli0701

Baumeister, R. F., Tice, D. M., \& Vohs, K. D. (2018). The strength model of self-regulation: Conclusions from the second decade of willpower research. Perspectives on Psychological Science, 13(2), 141-145. https://doi.org/ 10.1177/1745691617716946

Baumeister, R. F., Vohs, K. D., \& Tice, D. M. (2007). The strength model of self-control. Current Directions in Psychological Science, 16(6), 351-355. https://doi.org/ 10.1111/j.1467-8721.2007.00534.x

Bernecker, K., Herrmann, M., Brandstätter, V., \& Job, V. (2017). Implicit theories about willpower predict subjective well-being. Journal of Personality, 85(2), 136-150. https://doi.org/10.1111/jopy.12225

Bernecker, K., \& Job, V. (2015a). Beliefs about willpower are related to therapy adherence and psychological adjustment in patients with type 2 diabetes. Basic and Applied Social Psychology, 37(3), 188-195. https://doi. org/10.1080/01973533.2015.1049348

Bernecker, K., \& Job, V. (2015b). Beliefs about willpower moderate the effect of previous day demands on next day's expectations and effective goal striving. Frontiers in Psychology, 6(October), 1469. https://doi.org/10.3389/ fpsyg.2015.01496

Bernecker, K., \& Job, V. (2020). Too exhausted to go to bed: Implicit theories about willpower and stress predict bedtime procrastination. British Journal of Psychology, 111(1), 126-147. https://doi.org/10.1111/bjop.12382

Bertrams, A., \& Dickhäuser, O. (2009). Messung dispositioneller Selbstkontroll-Kapazität. Diagnostica, 55(1), 2-10. https://doi.org/10.1026/0012-1924.55.1.2

Blain, B., Hollard, G., \& Pessiglione, M. (2016). Neural mechanisms underlying the impact of daylong cognitive work on economic decisions. Proceedings of the National Academy of Sciences of the United States of America, 113(25), 6967-6972. https://doi.org/10.1073/pnas. 1520527113

Boland, W. A., Connell, P. M., \& Vallen, B. (2013). Time of day effects on the regulation of food consumption after activation of health goals. Appetite, 70, 47-52. https:// doi.org/10.1016/j.appet.2013.06.085

Cahill, L. E., Chiuve, S. E., Mekary, R. A., Jensen, M. K., Flint, A. J., Hu, F. B., \& Rimm, E. B. (2013). A prospective study of breakfast eating and incident coronary heart disease in a cohort of male U.S. health professionals. Circulation, 128(4), 337-343. https://doi.org/10. 1161/CIRCULATIONAHA.113.001474

Chow, J. T., Hui, C. M., \& Lau, S. (2015). A depleted mind feels inefficacious: Ego-depletion reduces self-efficacy to exert further self-control. European Journal of Social Psychology, 45(6), 754-768. https://doi.org/10.1002/ ejsp. 2120

Clarkson, J. J., Otto, A. S., \& Hirt, E. R. (2016). The malleable efficacy of willpower theories. Personality and Social Psychology Bulletin, 42(11), 1490-1504. https:// doi.org/10.1177/0146167216664059

Colles, S. L., Dixon, J. B., \& O'Brien, P. E. (2007). Night eating syndrome and nocturnal snacking: association with obesity, binge eating and psychological distress. International Journal of Obesity (2005), 31(11), 1722-1730. https://doi.org/10.1038/sj.ijo.0803664
Colley, R. C., Garriguet, D., Janssen, I., Craig, C. L., Clarke, J., \& Tremblay, M. S. (2011). Physical activity of Canadian adults: Accelerometer results from the 2007 to 2009 Canadian Health Measures Survey. Health Reports, 22(1), 7-13. https://doi.org/82-003-XPE

Cooper, A. R., Page, A., Fox, K. R., \& Misson, J. (2000). Physical activity patterns in normal, overweight and obese individuals using minute-by-minute accelerometry. European Journal of Clinical Nutrition, 54, 887-894. https://doi.org/10.1038/sj.ejcn.1601116

Crescioni, A. W., Ehrlinger, J., Alquist, J. L., Conlon, K. E., Baumeister, R. F., Schatschneider, C., \& Dutton, G. R. (2011). High trait self-control predicts positive health behaviors and success in weight loss. Journal of Health Psychology, 16(5), 750-759. https:// doi.org/10.1177/1359105310390247

Curtis, J., Burkley, E., \& Burkley, M. (2014). The rhythm is gonna get you: The influence of circadian rhythm synchrony on self-control outcomes. Social and Personality Psychology Compass, 8(11), 609-625. https://doi.org/10. $1111 / \mathrm{spc} 3.12136$

de Castro, J. M. (2004). The time of day of food intake influences overall intake in humans. The Journal of Nutrition, 134(1), 104-111. https://doi.org/10.1093/jn/ 134.1.104

de Castro, J. M. (2009). When, how much and what foods are eaten are related to total daily food intake. British Journal of Nutrition, 102(08), 1228. https://doi.org/10. 1017/S0007114509371640

Delose, J. E., VanDellen, M. R., \& Hoyle, R. (2015). First on the list: Effectiveness at self-regulation and prioritizing difficult exercise goal pursuit. Self and Identity, 14(3), 271-289. https://doi.org/10.1080/15298868.2014.983442

Dorris, D. C., Power, D. A., \& Kenefick, E. (2012). Investigating the effects of ego depletion on physical exercise routines of athletes. Psychology of Sport and Exercise, 13(2), 118-125. https://doi.org/10.1016/j. psychsport.2011.10.004

Eager, C., \& Roy, J. (2017). Mixed effects models are sometimes terrible [Unpublished manuscript]. Retrieved from http://arxiv.org/abs/1701.04858.

Edwards, L., Muller, K., Wolfinger, R., Qaqish, B., \& Schabenberger, O. (2008). An R2 statistic for fixed effects in the linear mixed model. Statistics in Medicine, 27, 6137-6157. https://doi.org/10.1002/sim

Evers, C., Dingemans, A., Junghans, A. F., \& Boevé, A. (2018). Feeling bad or feeling good, does emotion affect your consumption of food? A meta-analysis of the experimental evidence. Neuroscience and Biobehavioral Reviews, 92(May), 195-208. https://doi.org/10.1016/j. neubiorev.2018.05.028

Francis, Z., \& Job, V. (2018). Lay theories of willpower. Social and Personality Psychology Compass, 12(4), e12381. https://doi.org/10.1111/spc3.12381

Gelman, A., \& Loken, E. (2013). The garden of forking paths: Why multiple comparisons can be a problem, even when there is no "fishing expedition" or "phacking" and the research hypothesis [Unpublished manuscript]. Retrieved from http://www.stat.columbia.

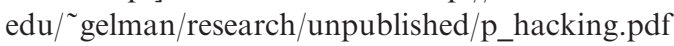

Godin, G., \& Shephard, R. J. (1985). A simple method to assess exercise behavior in the community. Canadian Journal of Applied Sport Sciences, 10(3), 141-146. 
Grogan, S. C., Bell, R., \& Conner, M. (1997). Eating sweet snacks: Gender differences in attitudes and behaviour. Appetite, 28, 19-31.

Hamrik, Z., Sigmundová, D., Kalman, M., Pavelka, J., \& Sigmund, E. (2014). Physical activity and sedentary behaviour in Czech adults: Results from the GPAQ study. European Journal of Sport Science, 14(2), 193-198. https://doi.org/10.1080/17461391.2013.822565

Hautzinger, M., \& Bailer, M. (1993). Allgemeine Depressions-Skala (ADS): Manual [Center for the Epidemiologic Studies Depression Scale (CES-D): Manual]. Weinheim: Beltz.

Heaven, P. C. L., Mulligan, K., Merrilees, R., Woods, T., \& Fairooz, Y. (2001). Neuroticism and conscientiousness as predictors of emotional, external, and restrained eating behaviors. International Journal of Eating Disorders, 30(2), 161-166. https://doi.org/10.1002/eat. 1068

Hofmann, W., Vohs, K. D., \& Baumeister, R. F. (2012). What people desire, feel conflicted about, and try to resist in everyday life. Psychological Science, 23(6), 582-588. https://doi.org/10.1177/0956797612437426

Housman, J., \& Dorman, S. (2005). The Alameda County Study: A systematic, chronological review. American Journal of Health Education, 36(5), 302-308. https:// doi.org/10.1080/19325037.2005.10608200

Huh, J., Shiyko, M., Keller, S., Dunton, G., \& Schembre, S. M. (2015). The time-varying association between perceived stress and hunger within and between days. Appetite, 89, 145-151. https://doi.org/10.1016/j.appet. 2015.02.001

Inzlicht, M., Schmeichel, B. J., \& Macrae, C. N. (2014). Why self-control seems (but may not be) limited. Trends in Cognitive Sciences, 18(3), 127-133. https:// doi.org/10.1016/j.tics.2013.12.009

Jaeger, T. F. (2009). Random effects: Should I stay or should I go? HLP/Jaeger Lab Blog. https://hlplab.word press.com/2009/05/14/random-effect-structure/

Job, V., Bernecker, K., Miketta, S., \& Friese, M. (2015). Implicit theories about willpower predict the activation of a rest goal following self-control exertion. Journal of Personality and Social Psychology, 109(4), 694-706. https://doi.org/10.1037/pspp0000042

Job, V., Dweck, C. S., \& Walton, G. M. (2010). Ego depletion - Is it all in your head? Implicit theories about willpower affect self-regulation. Psychological Science, 21(11), 1686-1693. https://doi.org/10.1177/ 0956797610384745

Job, V., Sieber, V., Rothermund, K., \& Nikitin, J. (2018). Age differences in implicit theories about willpower: Why older people endorse a nonlimited theory. Psychology and Aging, 33(6), 940-952. https://doi.org/ $10.1037 /$ pag0000285

Job, V., Walton, G. M., Bernecker, K., \& Dweck, C. S. (2015). Implicit theories about willpower predict selfregulation and grades in everyday life. Journal of Personality and Social Psychology, 108(4), 637-647. https://doi.org/10.1037/pspp0000014

Khare, A., \& Inman, J. J. (2006). Habitual behavior in American eating patterns: The role of meal occasions. Journal of Consumer Research, 32(4), 567-575. https:// doi.org/10.1086/500487

Klinger, J., Scholer, A., Hui, C. M., \& Molden, D. C. (2018). Effortful experiences of self-control foster lay theories that self-control is limited. Journal of Experimental Social Psychology, 78, 1-13. https://doi. org/10.1016/j.jesp.2018.04.006

Lauderdale, M. E., Yli-Piipari, S., Irwin, C. C., \& Layne, T. E. (2015). Gender differences regarding motivation for physical activity among college students: A selfdetermination approach. The Physical Educator, 72, 153-172. https://doi.org/10.18666/tpe-2015-v72-i5-4682

McDermott, S., Oliver, M., Iverson, D., \& Sharma, R. (2016). Effective techniques for changing physical activity and healthy eating intentions and behaviour: A systematic review and meta-analysis. British Journal of Health Psychology, 21, 827-841. https://doi.org/10. 1111/bjhp.12199

Mata, J., Thompson, R. J., Jaeggi, S. M., Buschkuehl, M., Jonides, J., \& Gotlib, I. H. (2012). Walk on the bright side: Physical activity and affect in major depressive disorder. Journal of Abnormal Psychology, 121(2), 297-308. https://doi.org/10.1037/a0023533

Matuschek, H., Kliegl, R., Vasishth, S., Baayen, H., \& Bates, D. (2017). Balancing Type I error and power in linear mixed models. Journal of Memory and Language, 94, 305-315. https://doi.org/10.1016/j.jml.2017.01.001

Millar, B. M. (2017). Clocking self-regulation: Why time of day matters for health psychology. Health Psychology Review, 11(4), 345-357. https://doi.org/10.1080/ 17437199.2017.1316673

Milyavskaya, M., Berkman, E. T., \& de Ridder, D. T. D. (2019). The many faces of self-control: Tacit assumptions and recommendations to deal with them. Motivation Science, 5, 79-85. https://doi.org/10.1037/ mot0000108

Milyavskaya, M., \& Inzlicht, M. (2017). What's so great about self-control? Examining the importance of effortful self-control and temptation in predicting real-life depletion and goal attainment. Social Psychological and Personality Science, 8(6), 603-611. https://doi.org/10. 1037/pspp0000045

Nezami, B. T., Lang, W., Jakicic, J. M., Davis, K. K., Polzien, K., Rickman, A. D., Hatley, K. E., \& Tate, D. F. (2016). The effect of self-efficacy on behavior and weight in a behavioral weight-loss intervention. Health Psychology, 35(7), 714-722. https://doi.org/10. 1037/hea0000378

Papies, E. K. (2016). Health goal priming as a situated intervention tool: How to benefit from nonconscious motivational routes to health behaviour. Health Psychology Review, 10(4), 408-424. https://doi.org/10. 1080/17437199.2016.1183506

Preacher, K. J., \& Selig, J. P. (2010). Monte Carlo method for assessing multilevel mediation: An interactive tool for creating confidence intervals for indirect effects in 1-1-1 multilevel models [Computer software]. http://quantpsy. org/

Radloff, L. S. (1977). The CES-D Scale: A self-report depression scale for research in the general population. Applied Psychological Measurement, 3, 385-401.

Rucker, D. D., Preacher, K. J., Tormala, Z. L., \& Petty, R. E. (2011). Mediation analysis in social psychology: Current practices and new recommendations. Social and Personality Psychology Compass, 5(6), 359-371. https://doi.org/10.1111/j.1751-9004.2011.00355.x

Salmon, S. J., Adriaanse, M. A., De Vet, E., Fennis, B. M., \& De Ridder, D. T. D. (2014). "When the going gets 
tough, who keeps going?" Depletion sensitivity moderates the ego-depletion effect. Frontiers in Psychology, 5, 647. https://doi.org/10.3389/fpsyg.2014.00647

Savani, K., \& Job, V. (2017). Reverse ego-depletion: Acts of self-control can improve subsequent performance in Indian cultural contexts. Journal of Personality and Social Psychology, 113(4), 589-607. https://doi.org/10. 1037/pspi0000099

Sellahewa, D. A., \& Mullan, B. A. (2015). Health behaviours and their facilitation under depletion conditions: The case of snacking. Appetite, 90, 194-199. https:// doi.org/10.1016/j.appet.2015.03.009

Sieber, V., Flückiger, L., Mata, J., Bernecker, K., \& Job, V. (2019). Autonomous goal striving promotes a nonlimited theory about willpower. Personality and Social Psychology Bulletin, 45(8), 1295-1307. https://doi.org/ $10.1177 / 0146167218820921$

Sjåstad, H., \& Baumeister, R. F. (2018). The future and the will: Planning requires self-control, and ego depletion leads to planning aversion. Journal of Experimental Social Psychology, 76(May), 127-141. https://doi.org/ 10.1016/j.jesp.2018.01.005

Sun, J., Rhemtulla, M., \& Vazire, S. (2020). Eavesdropping on missing data: What are people doing when they miss experience sampling reports? Personality and Social Psychology Bulletin. https://doi.org/10.31234/osf.io/ 5tcwd
Suresh, H. (2015, October 22). How different workout styles affect your mood, schedule and energy. JawBone Blog. https://jawbone.com/blog/how-different-workout-stylesaffect-your-mood-schedule-and-energy/\#ref4

Tangney, J., Baumeister, R. F., \& Boone, A. (2004). High self-control predicts good adjustment, less pathology, better grades, and interpersonal success. Journal of Personality, 72(2), 271-322.

Werner, K. M., Milyavskaya, M., Foxen-Craft, E., \& Koestner, R. (2016). Some goals just feel easier: Selfconcordance leads to goal progress through subjective ease, not effort. Personality and Individual Differences, 96, 237-242. https://doi.org/10.1016/j.paid.2016.03.002

West, S. G., Aiken, L. S., \& Krull, J. L. (1996). Experimental personality designs: analyzing categorical by continuous variable interactions. Journal of Personality, 64(1), 1-48.

Wilkowski, B. M., Ferguson, E. L., Williamson, L. Z., \& Lappi, S. K. (2018). (How) Does initial self-control undermine later self-control in daily-life? Personality and Social Psychology Bulletin, 44(9), 1315-1329. https://doi.org/10.1177/0146167218766857

Willis, T. A., Isasi, C. R., Mendoza, D., \& Ainette, M. G. (2007). Self-control constructs related to measures of dietary intake and physical activity in adolescents. Journal of Adolescent Health, 41(6), 551-558. https:// doi.org/10.1016/j.jadohealth.2007.06.013 